\title{
Study on the Cultural and Creative Industry for Sino- Russian Cooperation Development
}

\author{
Lili Qi \\ Heihe University \\ Heihe, China
}

\begin{abstract}
Creative economy is originated from the Britain at the end of twentieth century. Today, the creative economy is playing a more and more important role in national economy of various countries in the world, which has become one of the most potential industries. The creative industrial economy with Sino-Russian cultural industry as the lead also develops fast, which is accelerating China's economy development. This paper summarizes the important role and current situation of Sino-Russian industry, and through summing up advanced experiences of foreign cultural creative industry, the problems exist in Sino-Russian cultural creative industry development are analyzed, and the countermeasures for the expansion of Sino-Russian cultural creative development are proposed from the aspects such as the improvement of Sino-Russian creative and cultural property right system, talent cultivation for SinoRussian cultural and creative industry, and the formation of cultural and creative industry cluster in terms of industry chain.
\end{abstract}

Keywords-Sino-Russian; cultural and creative industry; development

\section{INTRODUCTION}

Report of the 19th National Congress of the Communist Party of China points out that, "the socialism with Chinese characteristics has entered into a new era; the main social contradiction has converted to the contradiction between people's increasing demand for good life and imbalance, insufficiency." The changes in the main contradiction of China society raises new and higher requirement, as the good life is not only the improvement of national GDP, enhancement of people's material level, or the increase in income, but also lies in the coordinated development of material civilization and spiritual civilization. Cultural and artistic products with high quality and the creative cultural industry are the components of a nation's cultural soft power, which is becoming the focus of competition among various countries, reflecting the nation's comprehensive national strength to a certain extent. In recent years, both China and Russia have carried out a series of activities and exhibitions publicizing the their own country's culture in the opposite country, which has promoted the cooperation of cultural and creative industry and launched a series of cultural exchange activities, boosting the Sino-Russian cultural industry

\footnotetext{
[Fund Project]

It is funded by the funds of "academic backbone of Heihe University" and "key teachers of Heihe University".
}

cooperation indirectly; in recent years, however, SinoRussian cultural exchange and cooperation is carried out frequently. The cooperation scale of the two countries in cultural and trade cooperation is expanded continuously and the trade volume is refreshed constantly. As a result, SinoRussian cultural and creative industry will become a new breakthrough for the economic and trade cooperation of the two countries in the future, and the development of SinoRussian creative cultural industry will play a more and more important role with the rapid development of globalization.

\section{IMPORTANT POSITION OF SINO-RUSSIAN CULTURAL AND CREATIVE INDUST RY IN REGIONAL ECONOMIC DEVELOPMENT}

As the product of the integration of culture, technology and economy, Sino-Russian cultural and creative industry has unique regional industry value orientation. The development scale and influence of the cultural and creative industry of China and Russia is increasing, and it will become the reference standard of the comprehensive competitiveness of the board areas of the two countries.

\section{A. Promote the Rapid Development of Regional Economy}

The foreign development experience and the main contradiction of current stage of China show that, the Chinese residents' demand for cultural products at the present stage has changed a lot. Residents have increasing demand for cultural and creative products, which will increase the rapid development of cultural and creative industry. As the main birthplace of Sino-Russian cultural and creative products, the Sino-Russian cultural and creative industry will enjoy a rapid development and become the new growth point of regional economy. From some foreign countries and regions with sound economic development we can see that, there is close relationship between economic development and the development of cultural and creative industry products. Especially when the economy development slows down, there exists the phenomenon of "flying against wind" in cultural and creative industry, making more and more countries and regions have strong ability of resisting risk. Sino-Russian cultural and creative industry also shows such stability and competitive advantage, urging the two countries to pay more attention to develop the Sino-Russian creative cultural industry, which will become the main driving force of regional economic development. 


\section{B. Increase the Number of Employed People}

The appearance of an emerging industry will drive the development of economy. Sino-Russian cultural and creative industry is a kind of emerging industry generated in the background of economic globalization with creativity as the core, strengthening the industry of a kind of main culture or cultural factors to develop and market intellectual property relying on technology, creativity and industrialization. As a result, as intellectually intensive industry, cultural and creative industry needs a large nu mber of high-quality labors, and even may drive the development of relevant industry, so it is bound to appear many jobs, mainly including the jobs in the aspects of radio, film and television, animation, audiovideo, media, visual arts, craft and design, sculpture, environmental art, advertising and decoration, costume design software and computer services, and it will create more job opportunities for the young people with creativity and ability.

\section{ST ATUS QUO OF SINO-RUSSIAN CULT URAL CREATIVE INDUSTRIES}

Cultural creative industry is newly rising strategic industry important for the New Normal of social development in China. Cultural creativity is a kind of cultural activity which borrows technique and wisdom and so on for kind of creativity, which is an integration of modern industries, showing the direction of advancing modern cultural industry. In the past years, China and Russia, basing them on friendly cooperation, have been driving the development of Sino-Russian cultural creative industries.

\section{A. Sino-Russian Cultural Creative Products Keep Increasing and the Influences of Cultural Industries Become Stronger Than Ever}

During the visit to Russia in Jul 2005, then-president $\mathrm{Hu}$ Jintao and Russian president Vladimir Putin declared in accordance with the Implementation Guidelines of the SinoRussian Treaty of Good Neighborliness, Friendship and Cooperation that China and Russia would hold the Russian Year in China in 2006, the Chinese Year in Russia in 2007, of which the most outstanding Sino-Russian cultural creative products were Cultural Year, Language Year and Tourism Year and so on, Such series of Sino-Russian cultural creative industries activities further deepen the cultural exchanges in a wider range. Besides, the cultural and art shows held mutually in these two countries have become important parts of cultural creative industries of the two countries. Russ ian oil paintings played an important role in the world history of arts, being highly strong in natural characters, in most recent years, Russian oil paintings have diverse schools, and talented painters are emerging one after another, and Russian oil painting shows and peak forums at high levels with high standards were even held in many cities in China, and more than 200 paintings could be introduced at one show. Russian oil paintings shows have been cultural creative activities with huge influences for the two countries. The animation art shows that combine modern and traditional and painting arts shows have succeeded in showing in Russia, which turns out that with proved economic policies and traditional excellent culture, China has valued the opening-up economy, keeping the continued increase of total trade of Sino-Russian cultural creative products. Keeping the influences of Sino-Russian cultural creative products increased continuously, and making the cultural output be stronger and stronger, which fully prove that the products of Sino-Russian cultural creative industries are increasing unceasingly, and the influences of Sino-Russian cultural creative products are increasing continuously.

\section{B. Highlighting the Position of Sino-Russian Cultural Creative Industries}

The environment and situations at home and abroad have changed in 2017, taking on diverse characteristics and trends, both China and Russia can well grasp the new environment and new opportunities to energetically drive Sino-Russian cultural creative industries, making all trades in the industries grow to some degree and achieving the stead growth of regional economy. Sino-Russian cultural creative industries are increasingly exposed to the sociality, markets and industrialization, varying with the reforms of Chinese cultural systems, such efforts have made Sino-Russian cultural creative industries be optimized gradually, showing a more important position than ever.

\section{Sino-Russian Cultural Creative Industries Lead Border City's Development Through Branding}

Based on the strength of multiple cultures, border cities between China and Russia have highlighted the unique "internationalized" air, and featured cultural creativities are focused on pattern transformation and structural adjustment; relying on rich cultural resources between China and Russia, more efforts are made to create Sino-Russian cultural brands in order to activate the featured cultural elements and internationalize them. Sino-Russian cultural creative industries will exert the active roles in leading cultural fashion, serving the society and boosting the economy development. In 2017, Heihe, a border city of Heilongjiang, is focused on creating featured Sino-Russian cultural creativity to color the residents' life and drive the urban development. The full interactions with different cultures integrated between border cities have displayed the soft strength of Heihe cultural development, leading a new position for border city's development. Heihe Sino-Russian cultural creative industries have gradually become a brandnew brand boosting the leapfrog development in Heihe city.

\section{MAIN PROBLEMS EXIST ING IN CHINESE CULTURAL CREATIVE INDUST RIES}

\section{A. Imperfect Laws and Regulations as well as Undeveloped Culture Safeguard System}

Nowadays, Chinese cultural creative industries have been on a track with high speed, and the contents and forms of Sino-Russian cultural creative industries are diversified as well, in the meantime, some problems concerned arise as well. For many years, the development of Chinese cultural creative industries are supported by policies and restricted by 
files, and there are no perfect leg islations applicable for the development of Sino-Russian cultural creative industries, and even there are no powerful directions in laws and systems. The imbalance between outdated cultural industries management systems and the rapid developing Sino-Russian cultural creative industries has been a bottleneck against the long term development of industrial economy. Therefore, it has been a problem urgent to solve for the Sino-Russian cultural creative industries to speed up establish and perfect basic laws and regulations, guarantee the sound development related to the Sino-Russian cultural creative industries and strengthen the self confidence in socialist culture.

\section{B. Lack of Technical Innovative Talents, Which Restrict the Industrial Development}

Human resources are key elements for the development of cultural creative industries, and the technical innovative talents for the Sino-Russian cultural creative industries should include the talents-related skills, educational background and production process and so on. Border cities between China and Russia are key regions for the development of Sino-Russian cultural creative industries, however, the regions are generally remote, which doest bad in cultivating and attracting excellent talents, such the SinoRussian cultural creative industries have to face the huge challenges such as shortage of talents, irrational structure and weak abilities of innovation. seen from do mestic education, the educational input, talents cultivation patterns in colleges as well as educational quality are still far to match with the cultural creative talents needed by the society and markets, which seriously block the development of Sino-Russian cultural creative industries. So it still has a long way to go in order to cultivate and development talents of Sino-Russian cultural creative industries.

\section{Incomplete Creative Industrial Chains and the Industrial Clusters Effect to Be Raised}

Inspiration and thought, creative spiritual products get cultural industries valuable, and the special Sino-Russian culture make the value added, achieving it through consumers' psychological experience and satisfaction of emotional appeal, and the Sino-Russian cultural creative industries firmly follow the industrial chains "creativity generation $\rightarrow$ investment $\rightarrow$ product $\mathrm{R} \& \mathrm{D} \rightarrow$ pricing $\rightarrow$ channel design $\rightarrow$ terminal users". At present, the SinoRussian cultural creative industries chains are in a serious disconnection, and there are no adequate push from creative product $R \& D$ to production, brand operation and till marketing, and no efficient communications can be established between enterprises, as a result, the creativity has been off the markets and vicious competitions exist between enterprises. The industrial clusters will form clusters effect, and the clusters effect of cultural creative industries still need to be improved.

\section{StRATEGIESTO BOOST THE SINO-RUSSIAN CULTURAL CREATIVE INDUST RIES}

\section{A. Establish and Improve the Property Right System of Sino-Russian Cultural Creative Industries}

At the beginning of cultural industries development, though Chinese governments according to experts' advice released some laws and regulations, yet due to the late start and rapid progress of the cultural industries, the establishment and implementation of many laws and regulations are still far falling behind the developed countries Most recently, facing the rapidly developing Sino-Russian cultural creative industries, we still have no perfect system, which is thought of big barrier against the sound development of the Sino-Russian cultural creative industries. In order to improve the laws and regulations of Sino-Russian cultural creative industries, first of all, we need to improve the property right and copyright protection, which is a core for the development of cultural creative industries. Second, we need to set up a complete set of property evaluation system for the Sino-Russian culture, which is a key for the cultural creative industries, in order to provide powerful guarantee for the Sino-Russian cultural creative industries and keep it well growing.

\section{B. Value the Talents Cultivation and Introduction Related to the Sino-Russian Cultural Creative Industries}

Talents are cores of cultural industries, and innovations are keys for the Sino-Russian cultural creative industries, talents are carriers of innovations, so the development of the Sino-Russian cultural creative industries has to depend on gathered talents. In order to attract talents, on the one hand, more efforts should be made to cultivate talents; on the other hand, more efforts should be made to introduce talents, cultivate and introduce talents related to the Sino-Russian cultural creative industries range and operation. Besides, local governments may release preferential policies to attract talents in order to solve the shortage of talents needed for the development of the Sino-Russian cultural creative industries.

\section{Form Sino-Russian Cultural Creative Industries Clusters}

The cultural creative industries clusters mean, in the field of cultural creative industries, there are all kinds of cultural creative enterprises and supporting organizations independent and connected with each other, which cluster in a certain region according to professional labor distribution and coordination, and it consists of all upstream and downstream enterprises on the cultural creative chains. The development of the Sino-Russian cultural creative industries should go on the way to the industrial clusters. The clusters have irreplaceable strengths, first of all, the industrial cluster pattern may efficiently connect relevant enterprises, saving consumption needed in production to the maximum, reducing the production costs greatly; second, the connections between enterprises make it easy for technical exchanges, during the joint cooperation and exploration, the professional level inside the clusters will be improved as 
well, from which more enterprises will get benefited and developed altogether.

\section{REFERENCES}

[1] Qi Lili, Yu Huiling, Researches on Development Strategies of Internationalizing Cultural Industries in Heilongjiang [J]. China Market, 2017(8).

[2] Dai Kui, Researches on Cultural Industries Development in China under the Background of Belt and Road Initiative [J] Modern Management science, 2017 (10).

[3] Zhang Jingcheng, 2015 Creative Industries Development Report in China [M]. Beijing: China Economic Publishing House, 2015.

[4] Bai Xiaoguang, Researches on Sino-Russian Cultural Industries Cooperation [J]. Siberian Studies, 2014 (12). 